\title{
Procalcitonin levels during pregnancy, delivery and postpartum*
}

\author{
Céline Paccolat ${ }^{1}$ ***, Stephan Harbarth ${ }^{2}$, Delphine \\ Courvoisier ${ }^{3}$, Olivier Irion ${ }^{1}$ and Begoña Martinez de \\ Tejada $^{1}$ \\ ${ }^{1}$ Department of Obstetrics and Gynecology, University of \\ Geneva Hospitals and Faculty of Medicine, Geneva, \\ Switzerland \\ ${ }^{2}$ Infection Control Program, University of Geneva \\ Hospitals and Faculty of Medicine, Geneva, Switzerland \\ ${ }^{3}$ Division of Clinical Epidemiology, University of Geneva \\ Hospitals and Faculty of Medicine, Geneva, Switzerland
}

\begin{abstract}
Aims: To determine the normal value ranges of procalcitonin (PCT) in women with uncomplicated pregnancies.

Methods: This prospective cohort study was conducted between May 2009 and February 2010 among 60 women without signs of clinical infection (31 vaginal deliveries, 29 cesarean sections) attending the maternity unit of the University of Geneva Hospitals. Sequential follow-up of PCT levels was performed at 24-28 weeks $(n=7), 36-40$ weeks $(n=60)$, at delivery $(n=59)$, and at days $2-3(n=58)$ and $10(\mathrm{n}=53)$ postpartum using a sensitive PCT assay with a functional sensitivity of $0.06 \mu \mathrm{g} / \mathrm{L}$.

Results: Median levels of PCT were: 24-28 weeks: 0.043 $\mu \mathrm{g} / \mathrm{L}$ (range $0.010-0.080$ ); 36-40 weeks: $0.061 \mu \mathrm{g} / \mathrm{L}$ (range 0.010-0.110); at delivery: $0.068 \mu \mathrm{g} / \mathrm{L}$ (range 0.010-0.170); days 2-3: $0.200 \mu \mathrm{g} / \mathrm{L}$ (range 0.030-5.00); and day 10: 0.060 $\mu \mathrm{g} / \mathrm{L}$ (range $0.020-0.120$ ). At days $2-3$ postpartum, three women had a PCT level between $0.25 \mu \mathrm{g} / \mathrm{L}$ and $0.5 \mu \mathrm{g} / \mathrm{L}$ and two women had a level higher than $0.5 \mu \mathrm{g} / \mathrm{L}$.

Conclusions: This study provides reference values for PCT during the third trimester, at delivery and at the immediate

\footnotetext{
*Condensation: This study gives reference values of procalcitonin during the third trimester, at delivery and the immediate postpartum period in pregnant women without clinical infection.

Source of the study: University of Geneva Hospitals.

Funding: This work was supported by a grant from the University of Geneva Hospitals (\# PRD 08-II-8).

**Corresponding author:

Céline Paccolat, MD

Department of Obstetrics and Gynecology

University of Geneva Hospitals

30 Boulevard de la Cluse

1211 Geneva

Switzerland

Tel.: +41 223100466

Fax: +41 227895830

E-mail: cpaccolat@gmail.com
}

postpartum period. A cut-off PCT level of $0.25 \mu \mathrm{g} / \mathrm{L}$ can be used during the third trimester, at delivery, and at the immediate postpartum period to rule out infection.

Keywords: Delivery; normal values range; postpartum; pregnancy; procalcitonin.

\section{Introduction}

Early detection of infection is of the utmost importance in obstetrics and failure to diagnose it can lead to severe complications for the mother, the fetus, and the newborn [16]. However, infection during pregnancy is not reliably predicted by commonly used laboratory tests, such as white cell counts (WBC), neutrophil count or vaginal bacterial culture [19]. Indeed, a physiologic increase in WBC exists during uncomplicated pregnancy and the threshold to diagnose an infection has to be modified during pregnancy [5]. In addition, clinical signs, such as fever and fetomaternal tachycardia usually appear late [8]. C-reactive protein (CRP) is a biological blood marker frequently used as a predictor of intraamniotic infections (IAI), [19, 8] but a recent meta-analysis has shown that there is no evidence to support its use for the early diagnosis of IAI [23]. Therefore, an accurate and rapid marker for the diagnosis of early infection in the context of pregnancy complications, such as preterm labor or the premature rupture of membranes, is urgently needed.

Procalcitonin (PCT), a prohormone consisting of 116 amino acids, is a normal precursor of the active hormone calcitonin and was first described in 1990 as a sepsis-induced protein [1]. PCT levels are elevated in severe bacterial infections, but remain low in viral infections and non-specific inflammatory disease $[1,10]$. In healthy individuals, the normal PCT level is lower than $0.2 \mathrm{ng} / \mathrm{mL}$ [9]. Values increase rapidly in pathologic conditions, leading to systemic inflammatory response syndrome (SIRS), [15] and a cut-off level of $0.25 \mu \mathrm{g} / \mathrm{L}$ has been recently suggested for considering the use of antibiotic treatment [15].

Contradictory results have been reported in the few studies that have measured PCT levels during pregnancy [2, 20-22]. Therefore, there is a need to better define normal PCT values in pregnant women before using PCT levels as a tool in the management of infectious complications during the perinatal period.

The objective of this study was to determine the normal value ranges of PCT during the third trimester, at delivery, and during postpartum in pregnant women without clinical infection. 


\section{Material and methods}

\section{Patient population}

The study was conducted at the Department of Gynecology and Obstetrics of the University Hospitals of Geneva, Geneva, Switzerland, a tertiary care hospital with approximately 4000 deliveries per year. The study protocol was approved by the institutional Ethics Committee and written informed consent was obtained from each participant. We included women with singleton pregnancies, older than 18 years, gestational age $\geq 24$ weeks, and able to consent during the prenatal consultation. Exclusion criteria were fever $\left(\geq 38^{\circ} \mathrm{C}\right)$, preterm labor, symptomatic urinary infection, preterm rupture of membranes, preeclampsia and hemolysis, elevated liver enzymes, and low platelet count (HELLP) syndrome. Blood samples were taken at five time-points: $24-28$ weeks, 36-40 weeks, delivery (after placental delivery), and at days 2-3 (D2-3) and day 10 postpartum (D10). We collected data on age, gestational age, parity, smoking status, previous medical history, labor/delivery, postpartum complications and neonatal outcome.

\section{Laboratory test}

PCT was measured using a rapid sensitive assay (Kryptor PCT, BRAHMS, Hennigsdorf, Germany) based on a sandwich-typed immunometric test with a lower detection level of $0.02 \mu \mathrm{g} / \mathrm{L}$ (functional sensitivity, $0.06 \mu \mathrm{g} / \mathrm{L}$ ). Inter-assay and intra-assay variations are as follows: for $0.1 \mu \mathrm{g} / \mathrm{L}, 15 \%$ for both; for $0.2 \mu \mathrm{g} / \mathrm{L}, 6 \%$ and $10 \%$, respectively, and for levels above $0.3 \mu \mathrm{g} / \mathrm{L},<6 \%$ and $5 \%$, respectively (data from our laboratory and BRAHMS).

\section{Statistical analysis}

Data are expressed as medians, interquartile ranges, extreme values and box-plots for each time-period considered. PCT levels between sampling periods and according to mode of delivery (vaginal vs. cesarean section) were compared using the paired Wilcoxon and Mann-Whitney $U$-tests, respectively. Calculations were performed with EpiInfo (Centers for Disease Prevention and Control, Atlanta, GA, USA) and SPSS version 17 (SPSS Inc., Chicago, IL, USA); graphs were drawn using $\mathrm{R} 2.10 .1$ ( $\mathrm{R}$ project). We calculated the specificity of the threshold of $0.25 \mu \mathrm{g} / \mathrm{L}$ to rule out infection as this PCT value is commonly used in clinical practice to manage infectious complications.

\section{Results}

From May 2009 to February 2010, 60 pregnant women were included and followed prospectively. In group 1 (vaginal delivery group), we included 31 women (28 spontaneous vaginal deliveries and three instrumental deliveries). In group 2 (cesarean section [C-section]), we included 29 women (26 elective and three emergency). In order to have two homogeneous groups regarding the mode of delivery, we included 21 women at 35-36 weeks gestation when the indication for delivery by $\mathrm{C}$-section was established. The main characteristics of study participants according to the mode of delivery are presented in Table 1 . Only maternal age at delivery was different between the $\mathrm{C}$-section group and the vaginal delivery group ( $\mathrm{P}=0.001)$. Four women (two in each group) had a history of urinary infection prior to pregnancy, and two

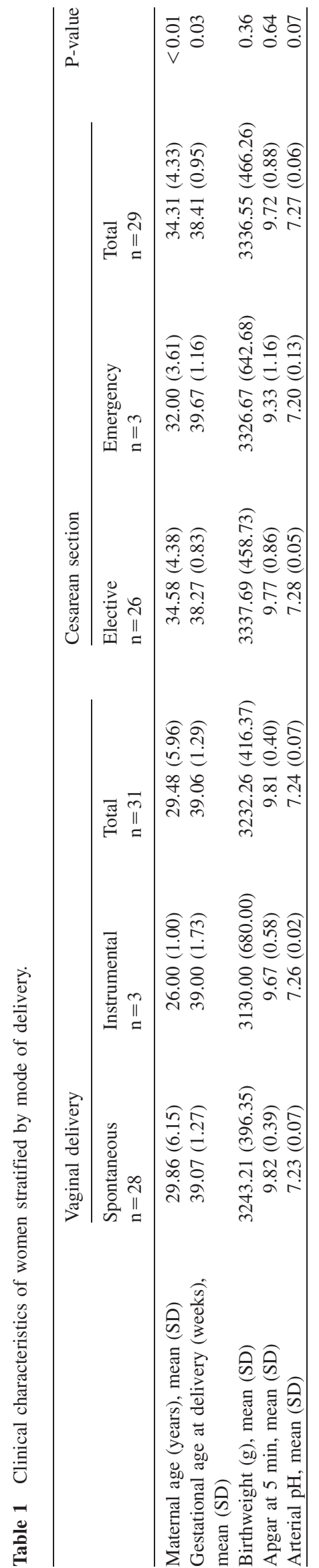




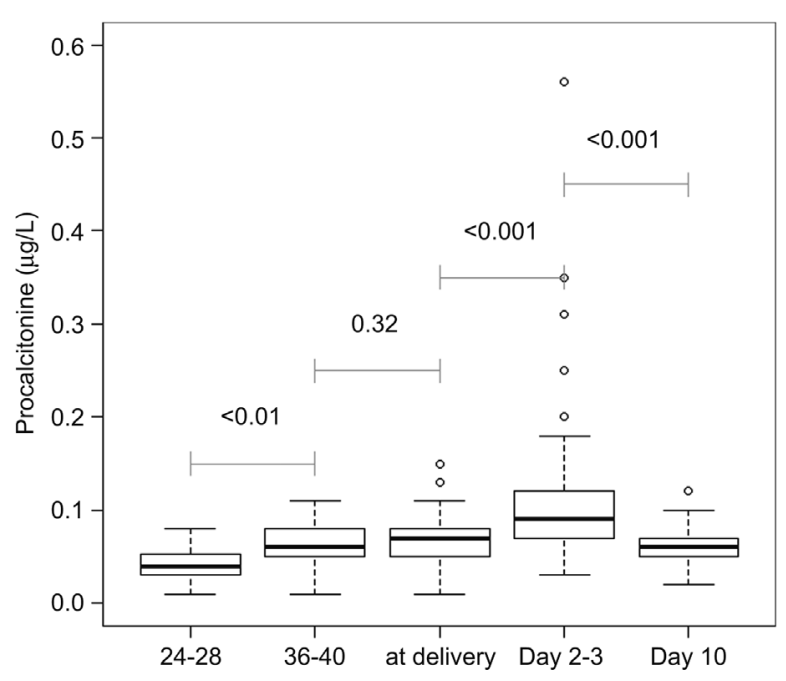

Figure 1 Evolution of procalcitonin levels at the end of pregnancy (24-28 weeks, 36-40 weeks), immediately after delivery and in the postpartum period (days 2-3 and day 10). The boxes represent $50 \%$ of the values, the horizontal bar inside the median, and the lower and upper bars the $10^{\text {th }}$ and $90^{\text {th }}$ percentiles, respectively.

(one per group) of chronic hypertension. Three women were HIV seropositive (one in the vaginal group and two in the C-section group).

During pregnancy, one woman in each group received preemptive antibiotic treatment after inclusion for recurrent asymptomatic bacteriuria. Their PCT levels were low [0.06 (vaginal) and $0.07 \mu \mathrm{g} / \mathrm{L}$ (C-section) at 24-28 weeks]. One woman had a spontaneous preterm vaginal delivery and developed clinical choriamnionitis during labor (fever $38^{\circ} \mathrm{C}$, WBC $27.5 \mathrm{~g} / \mathrm{L}$, and high CRP $13 \mathrm{mg} / \mathrm{L}$ ). Her PCT values at delivery $(0.17 \mu \mathrm{g} / \mathrm{L})$ and at D3 postpartum $(0.51 \mu \mathrm{g} / \mathrm{L})$ were excluded from the analysis. Eleven women in group 1 received antibiotic treatment during labor (nine for prevention of group B streptococcus neonatal sepsis, one for endocarditis prophylaxis, and the woman with clinical chorioamnionitis). In group 2 , all women received antibiotic prophylaxis $\left(1^{\text {st }}\right.$ generation cephalosporin) after umbilical cord clamping.

PCT levels from all 60 women at each sampling period are shown in Figure 1. Median levels for each time period were as follows: $24-28$ weeks: $0.043 \mu \mathrm{g} / \mathrm{L}$ (range $0.010-$ 0.080 ); 36-40 weeks: $0.061 \mu \mathrm{g} / \mathrm{L}$ (range 0.010-0.110); at delivery: $0.068 \mu \mathrm{g} / \mathrm{L}$ (range $0.010-0.170$ ); D2-3: $0.200 \mu \mathrm{g} / \mathrm{L}$ (range 0.030-5.00); and D10: $0.060 \mu \mathrm{g} / \mathrm{L}$ (range 0.0200.120). PCT levels significantly increased in the third trimester of pregnancy and between delivery and D3 postpartum. At D3, five of 57 women $(8.8 \%)$ had values $\geq 0.25$ $\mu \mathrm{g} / \mathrm{L}(0.25,0.31,0.35,0.56$ and 5.00, respectively (Table 2$)$ without signs of infection during delivery and postpartum. Using this threshold, the specificity of PCT levels at D3 postpartum was $91.1 \%$ (exact $95 \%$ CI, 80.4; 97.0). The woman with a D3 PCT level of $5.0 \mu \mathrm{g} / \mathrm{L}$ had received antibiotic treatment during delivery (PCT value at delivery, 0.07 $\mu \mathrm{g} / \mathrm{L})$ for endocarditis prophylaxis and the following day received an epidural blood patch for a lumbar puncture. Her
PCT returned to normal at D10 $(0.12 \mu \mathrm{g} / \mathrm{L})$. During the other time periods, the specificity of the threshold of $0.25 \mu \mathrm{g} / \mathrm{L}$ was $100 \%$ as no women had a PCT value $\geq 0.25 \mu \mathrm{g} / \mathrm{L}$.

The evolution of PCT levels according to the mode of delivery are shown in Table 2 and Figure 2. The increase of PCT levels between 24-28 weeks and 36-40 weeks was not statistically significant in the $\mathrm{C}$-section group and was probably due to the low number of women sampled at 24-28 weeks. In contrast, the elevated levels between delivery and D3 was only significant in the group of women delivering by C-section. At D10, PCT levels significantly decreased among both groups, but they were significantly higher in group 2 compared with group 1 .

\section{Comment}

PCT is a promising biomarker of infection and ubiquitously expressed in response to bacterial endotoxins and cytokines [15]. In the present study, we established normal PCT levels for the third trimester of pregnancy, at delivery, and the immediate postpartum period in women without acute infection delivering vaginally or by $\mathrm{C}$-section.

Our study demonstrates that PCT levels increase significantly at the end of pregnancy and between delivery and D3 postpartum, with a decrease at D10 postpartum. PCT levels are higher at D3 postpartum than at any other time-point and this elevation is also associated with the mode of delivery, being more marked after $\mathrm{C}$-section. Labor and delivery stimulates the inflammatory cascade and this can probably explain the slight elevation of PCT levels at D3 [12]. Previous studies have shown that PCT concentrations rise after abdominal surgery through the liberation of endotoxins without bacterial translocation [13,3] and this possibly accounts for the more pronounced elevation among women delivering by C-section.

Regardless of the PCT increase observed in our study, PCT levels at the end of pregnancy, at delivery, and during the postpartum period are within the same levels observed in other non-infected adult populations [9, 15]. Our results are in agreement with those of Assumma et al. who also found very low levels of PCT at delivery (geometric mean, $0.01 \mu \mathrm{g} / \mathrm{L}$ ), but using a different PCT assay than the one used in our study [12]. In contrast, Torbé et al. found very high PCT values during the second half of pregnancy (mean, $1.06 \mu \mathrm{g} / \mathrm{L}$ ) [21] and at delivery (medium PCT value, $0.71 \mu \mathrm{g} / \mathrm{L}$ ), thus precluding the use of PCT in the management of infectious complications during pregnancy [20].

We have assessed the specificity of the cut-off level of $0.25 \mu \mathrm{g} / \mathrm{L}$ to rule out infection as this value is currently used to diagnose systemic infections and to guide the use of antibiotics in infected adult populations [4, 9, 17]. In our study, this value has a specificity of $91.1 \%$ at D3 postpartum and of $100 \%$ at the other four time-periods as all women had PCT levels below this threshold. This is in agreement with other studies showing specificities ranging from 78-96\% [10, 11, 14, 18]. Causes for "false-positive"' PCT values $(>0.25 \mu \mathrm{g} / \mathrm{L})$, such as severe or surgical trauma, have been 
Table 2 Evolution of PCT levels (median and ranges) at the end of pregnancy and in the postpartum according to the mode of delivery.

\begin{tabular}{|c|c|c|c|c|c|c|c|c|c|}
\hline & \multicolumn{4}{|c|}{ Vaginal delivery $(\mathrm{n}=31)$} & \multicolumn{4}{|c|}{ Cesarean section $(n=29)$} & \multirow[t]{2}{*}{ P-value } \\
\hline & $\mathrm{n}^{*}$ & Range & Median & $\begin{array}{l}\text { Women }(\mathrm{n}) \\
\text { with values } \\
>0.25 \mu \mathrm{g} / \mathrm{L}\end{array}$ & $\mathrm{n}^{*}$ & Range & Median & $\begin{array}{l}\text { Women }(\mathrm{n}) \\
\text { with values } \\
>0.25 \mu \mathrm{g} / \mathrm{L}\end{array}$ & \\
\hline At $24-28$ weeks & 29 & $0.01-0.07$ & 0.04 & 0 & $8 * *$ & $0.03-0.08$ & 0.05 & 0 & 0.14 \\
\hline At $36-40$ weeks & 31 & $0.01-0.11$ & 0.06 & 0 & 29 & $0.03-0.10$ & 0.07 & 0 & 0.05 \\
\hline At delivery & 29 & $0.01-0.15$ & 0.07 & 0 & 29 & $0.02-0.11$ & 0.07 & 0 & 0.40 \\
\hline At day $2-3$ & 28 & $0.03-5.00$ & 0.07 & 2 & 29 & $0.05-0.56$ & 0.10 & 3 & $<0.01$ \\
\hline At day 10 & 27 & $0.02-0.12$ & 0.05 & 0 & 26 & $0.03-0.10$ & 0.07 & 0 & $<0.01$ \\
\hline
\end{tabular}

*Two samples at 24-28 weeks, one during labor, two at D2-3 and seven at D10 were missed.

**Twenty-one women were included at 35-36 weeks of gestation when the indication for cesarean section was established. No sampling at 24-28 weeks.

identified in other studies [7]. In our study, an example of "false-positive"' was the woman who had 5.0 $\mu \mathrm{g} / \mathrm{L}$ at D3 postpartum following an epidural blood patch for a lumbar puncture, which is probably explained by an inflammatory non-septic state.

A limitation of this study is that we did not collect data on women with infectious complications and cannot assess the sensitivity of the test. One woman had clinical chorioamniotitis and her PCT values $(0.17 \mu \mathrm{g} / \mathrm{L}$ at delivery and $0.51 \mu \mathrm{g} / \mathrm{L}$ at D3) were excluded from the analysis. Nevertheless, those values were high, thus confirming the hypothesis that PCT might be used for the diagnosis of infectious complications during pregnancy. Further studies, including case-control studies, are necessary to validate these data.
Additionally, further analyses should be conducted to evaluate the efficacy of PCT in guiding the duration of antibiotic treatment in pregnant women.

\section{Conclusion}

In conclusion, our study provides normal PCT levels for the third trimester of pregnancy, at delivery, and the immediate postpartum period. PCT values are generally low, but with a slight increase at D3 postpartum, especially among women delivering by C-section. The PCT level of $0.25 \mu \mathrm{g} / \mathrm{L}$ can be used to rule out infection during the perinatal period. However, additional studies should be conducted to assess the
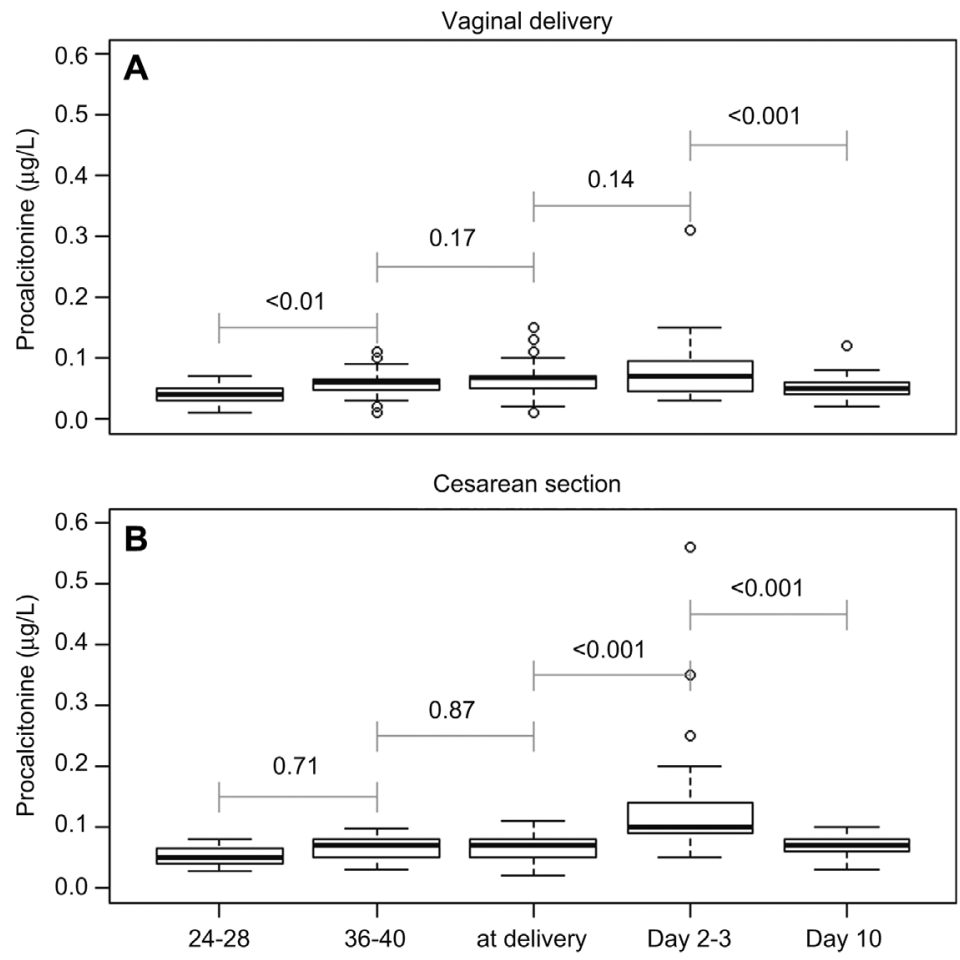

Figure 2 (A, B) Evolution of procalcitonin levels at the end of pregnancy (24-28 weeks, 36-40 weeks), immediately after delivery and in the postpartum period (days 2-3 and day 10) according to mode of delivery. 
usefulness of PCT measurements in pregnant women with suspected infection.

\section{Acknowledgements}

We thank Véronique Othenin-Girard and Rhimou Azbar for their help with the recruitment of women included in the study and the "Arcade des sages-femmes" (private midwives' association) for the conduct of blood sampling at D10. We also thank Dr Michel Boulvain for assisting us with the statistical analysis, Dr Olivier Golaz for performing the laboratory analysis, and Professor Denis Hochstrasser for his support. This work was supported by a competitive Grant from the University Hospital of Geneva (PRD 08-II-8).

\section{References}

[1] Assicot M, Gendrel D, Carsin H, Raymond J, Guilbaud J, Bohuon C. High serum procalcitonin concentrations in patients with sepsis and infection. Lancet. 1993;341:515-8.

[2] Assumma M, Signore F, Pacifico L, Rossi N, Osborn JF, Chiesa C. Serum procalcitonin concentrations in term delivering mothers and their healthy offspring: a longitudinal study. Clin Chem. 2000;46:1583-7.

[3] Bolke E, Jehle PM, Graf M, Baier A, Wiedeck H, Steinbach $\mathrm{G}$, et al. Inflammatory response during abdominal and thyroid surgery: a prospective clinical trial on mediator release. Shock. 2001;16:334-9.

[4] Bouadma L, Luyt CE, Tubach F, Cracco C, Alvarez A, Schwebel C, et al. Use of procalcitonin to reduce patients' exposure to antibiotics in intensive care units (PRORATA trial): a multicentre randomised controlled trial. Lancet. 375 : 463-74.

[5] Branch DW. Physiologic adaptations of pregnancy. Am J Reprod Immunol. 1992;28:120-2.

[6] Chen FC, Sarioglu N, Buscher U, Dudenhausen JW. Lipopolysaccharide binding protein in the early diagnosis of intraamniotic infection of pregnant women with premature rupture of the membranes. J Perinat Med. 2009;37:135-9.

[7] Christ-Crain M, Muller B. Procalcitonin in bacterial infections - hype, hope, more or less? Swiss Med Wkly. 2005; 135:451-60.

[8] Gomez R, Ghezzi F, Romero R, Munoz H, Tolosa JE, Rojas I. Premature labor and intra-amniotic infection. Clinical aspects and role of the cytokines in diagnosis and pathophysiology. Clin Perinatol. 1995;22:281-342.

[9] Graf J-D. La procalcitonine, un marqueur (idéal?) des états septiques. Pipette. 2007;6:12-5.

[10] Harbarth S, Holeckova K, Froidevaux C, Pittet D, Ricou B, Grau GE, et al. Diagnostic value of procalcitonin, interleukin-6, and interleukin- 8 in critically ill patients admitted with suspected sepsis. Am J Respir Crit Care Med. 2001;164:396402.
[11] Hausfater P. Procalcitonin measurement in adult clinical practice. Rev Med Interne. 2007;28:296-305.

[12] Jabbour HN, Sales KJ, Catalano RD, Norman JE. Inflammatory pathways in female reproductive health and disease. Reproduction. 2009;138:903-19.

[13] Maier M, Wutzler S, Lehnert M, Szermutzky M, Wyen H, Bingold T, et al. Serum procalcitonin levels in patients with multiple injuries including visceral trauma. J Trauma. 2009; 66:243-9.

[14] Muller B, Harbarth S, Stolz D, Bingisser R, Mueller C, Leuppi J, et al. Diagnostic and prognostic accuracy of clinical and laboratory parameters in community-acquired pneumonia. BMC Infect Dis. 2007;7:10.

[15] Müller B, Schuetz P, Christ-Crain M. Procalcitonine. Forum Med Suisse. 2008;8:388-90.

[16] O'Shea TM, Klinepeter KL, Meis PJ, Dillard RG. Intrauterine infection and the risk of cerebral palsy in very low-birthweight infants. Paediatr Perinat Epidemiol. 1998;12:72-83.

[17] Schuetz P, Christ-Crain M, Thomann R, Falconnier C, Wolbers $\mathrm{M}$, Widmer I, et al. Effect of procalcitonin-based guidelines vs. standard guidelines on antibiotic use in lower respiratory tract infections: the ProHOSP randomized controlled trial. J Am Med Assoc. 2009;302:1059-66.

[18] Schuetz P, Christ-Crain M, Müller B. Procalcitonin and other biomarkers to improve assessment and antibiotic stewardship in infections - hope for hype? Swiss Med Wkly. 2009;139: $318-26$.

[19] Sereepapong W, Limpongsanurak S, Triratanachat S, Wannakrairot P, Charuruks N, Krailadsiri P. The role of maternal serum C-reactive protein and white blood cell count in the prediction of chorioamnionitis in women with premature rupture of membranes. J Med Assoc Thai. 2001;84(Suppl 1): S360-6.

[20] Torbe A. Maternal plasma procalcitonin concentrations in pregnancy complicated by preterm premature rupture of membranes. Mediators Inflamm. 2007;2007:35782.

[21] Torbe A, Czajka R. Maternal plasma procalcitonin concentrations in patients with preterm labor and intact membranes prediction of preterm delivery and admission-to-delivery interval. J Perinat Med. 2004;32:332-6.

[22] Torbe A, Czajka R. Are vaginal fluid procalcitonin levels useful for the prediction of subclinial infection in patients with preterm premature rupture of membranes? J Obstet Gynaecol Res. 2005;31:464-70.

[23] Trochez-Martinez RD, Smith P, Lamont RF. Use of C-reactive protein as a predictor of chorioamnionitis in preterm prelabour rupture of membranes: a systematic review. Br J Obstet Gynaecol. 2007;114:796-801.

The authors stated that there are no conflicts of interest regarding the publication of this article.

Received March 5, 2011. Revised May 22, 2011. Accepted May 25, 2011. Previously published online August 12, 2011. 